Corresponding Author:

Gusliani Eka Putri

guslianiekaputri@gmail.com

Received: 19 February 2019

Accepted: 5 March 2019

Published: 16 April 2019

Publishing services provided by

Knowledge E

(c) Gusliani Eka Putri et al. This article is distributed under the terms of the Creative Commons

Attribution License, which

permits unrestricted use and

redistribution provided that the

original author and source are credited.

Selection and Peer-review under the responsibility of the ICBSA Conference Committee.

\section{High Performance of Photocatalytic Activity of Cerium Doped Silika Mesoporous Operating under Visible light Irradiation}

\author{
Gusliani Eka Putri ${ }^{1}$, Syukri Arief ${ }^{2}$, Novesar Jamarun ${ }^{2}$, Feni Rahayu Gusti ${ }^{1}$, and \\ Adel Fisli ${ }^{3}$ \\ ${ }^{1}$ Sekolah Tinggi IImu Kesehatan Syedza Saintika, West Sumatera, Indonesia \\ ${ }^{2}$ Department of Chemistry, Faculty of Mathematic and Science, Universitas Andalas, West \\ Sumatera, Indonesia \\ ${ }^{3}$ Badan Tenaga Nuklir Nasional (BATAN), Kawasan Puspiptek, Serpong, Indonesia
}

\section{Abstract}

The photocatalytic activity of cerium oxide increased after being doped with mesoporous silica. Increasing activity photocatalytic as shown from BET, TEM, and DRS UV Vis data. Results showed the surface area of Cerium oxide doped of mesoporous silica advanced from 97.44 to $736.88 \mathrm{~m}^{2} \mathrm{~g}^{-1}$. High surface area caused increased photocatalytic activity. DRS UV VIS Analysis showed that cerium oxide nanoparticles band gap value of $2.43 \mathrm{eV}$ and mesoporous silica band gap value $1.27 \mathrm{eV}$. The smaller bandgap results in effective photocatalysts used in visible light. Degradation methylene blue had done used photochatalyst Ceria, MS-Ce dan MMS-Ce, and visible irradiation. This study determines the optimum weight of Ceria, MS-Ce and MMS-Ce catalysts, optimum radiation time of Ceria, MS-Ce and MMS-Ce catalysts and the effectiveness of photodegradation of methylene blue, MS-Ce and MMS-Ce at optimum conditions. Degradation of Methylene blue was analyzed using a UV-Vis spectrometer. The results showed that the optimum conditions obtained were the optimum catalyst weight of Ceria, MS-Ce, and MMS-Ce, were $50 \mathrm{mg}, 50 \mathrm{mg}$, and $40 \mathrm{mg}$. The optimum time for Ceria, MS-Ce and MMS-Ce photocatalyst degrades used visible light was 150 minutes, 300 minutes and 120 minutes. The effectiveness of methylene blue degradation using Ceria, MS-Ce and MMS-Ce photocatalysts was 68.85\%, 97.38\%, and 99.98\%.

Keywords: cerium oxide, silica mesoporous, photocatalytic

\section{Introduction}

Currently the development and progress of the textile industry in Indonesia has developed very rapidly. The textile industry can provide benefits for human life. But the 
This was because in textile production waste was always produced, one of which is the dye waste [1]. Dyestuff waste is an organic compound that is difficult to decompose, resistant, and toxic [2]. If the waste is discharged into the nearest waters, it will cause environmental pollution [3]. In the textile industry, methylene blue is one of the thiazine dyes that are often used, because the price is economical and easy to obtain [4]. Methylene blue dye is a basic dye that is important in the process of coloring the skin, mori cloth, cotton cloth, and tannin. The use of methylene blue can cause several effects, such as irritation of the digestive tract if swallowed, causing cyanosis if inhaled, and irritation to the skin if touched by the skin [5]. Many methods are used to describe dyestuff waste including adsorption and activated sludge, but those method haves many weaknesses. An alternative photodegradation method has been developed using semiconductor photocatalysts and ultraviolet light. TiO2 which was dispersed in natural zeolite and its application for photodegradation of congo red, states that the photodegradation method was a relatively inexpensive and easy to implement method. This photodegradation can decompose dyes into components that were safe for the environment [6]. The photodegradation of methyl orange using $\mathrm{ZnO}$ and UV light, the use of photocatalyst semiconductors has several advantages including being able to carry out total mineralization of organic pollutants, the cost was cheap, the process was relatively fast, non-toxic, and has long-term use capability [7]. The photocatalyst material used in the photodegradation method is a semiconductor, such as: $\mathrm{TiO} 2, \mathrm{ZnO}, \mathrm{CeO} 2$ and $\mathrm{Al}_{2} \mathrm{O}_{3}$. Photocatalyst activity increased by absorbing UV light, resulting in electrons and holes. Hole was a positive hole caused by electron displacement. Electrons and holes are the most important species to begin the photodegradation process. Currently the use of photocatalyst materials, such as $\mathrm{CeO} 2(\mathrm{Eg}=3.2 \mathrm{eV})$ was a concern for researchers to develop as photocatalysts because of their better properties than $\mathrm{TiO} 2$, $\mathrm{ZnO}$, and $\mathrm{Al}_{2} \mathrm{O}_{3}$. Based on this reason, researchers used $\mathrm{CeO} 2$ photocatalysts that were doped with modified mesoporous silica to decompose methylene blue dye.

\section{Materials and Methods}

\subsection{Chemicals and reagents}

Tetraethyl orthosilicate (TEOS) for the silica source, Cetyltrimethylammonium bromide (CTAB) for surfactant, Cerium (III) nitrate hexahydrate $(\mathrm{Ce}(\mathrm{NO} 3) 3.6 \mathrm{H} 2 \mathrm{O})$ used for precursor of $\mathrm{CeO} 2$, Aniline(C6H5NH2) for Base Bronsted, Besi (III) Chloride (FeCl3) for Acid Lewis, 2-propanol and methylene blue. All chemicals used purely from Merck. 
The equipment used in this study are: a set of glassware, analytic scales, $\mathrm{pH}$ meters, magnetic stirrers (magnetic stirrer), hot plates, radiation boxes, black plastic, UV C lamps, centrifuges, and SP-870 spectrophotometers.

\subsection{Determination of the maximum wavelength of methylene blue solution}

Methylene blue solution with a concentration of $2 \mathrm{ppm}$ measured its absorbance at various wavelengths, ranging from $550 \mathrm{~nm}-675 \mathrm{~nm}$. The results obtained are depicted on the graph with absorbance as the $y$ axis and the wavelength of light as the $x$ axis. The maximum wavelength was the wavelength that gives the maximum absorbance value.

\subsection{Making a calibration curve for a methylene blue solution}

Methylene blue standard solutions with concentrations of 1, 2, 3 and $4 \mathrm{ppm}$ were measured by absorbance at the maximum wavelength of methylene blue. Next, a calibration curve was created by plotting concentration and absorbance.

\subsection{Determination of the optimum time of Ceria, MS-Ce and MMS- Ce photocatalyst for photodegradation process of methylene blue}

Four $100 \mathrm{~mL}$ beker glasses which have been wrapped in black plastic each filled with $100 \mathrm{~mL}$ of $20 \mathrm{ppm}$ methylene blue solution. $50 \mathrm{mg}$ of Ceria, MS-Ce and MMS-Ce and 1 cup of glass without catalyst were added to each glass beaker. The glass beaker is inserted into the radiation box and the black plastic wrap was released. Furthermore, the beaker glass was irradiated with Visibel lamps for 30.60,90,120,150,180,210,240,270, and 300 minutes, during the irradiation process with Visible light the solution was stirred with magnetic stirrer. After the radiation process, the suspension of each beker glass was centrifuged at a speed of $4000 \mathrm{rpm}$ for 10 minutes. The solution was then decanted to separate the supernatant and sediment. The supernatant obtained from each glass beaker measured its absorbance by UV-Vis spectrophotometer at the maximum wavelength of methylene blue. The absorbance value obtained was then entered into the linear regression equation of the methylene blue solution, so that the methylene 
blue concentration was obtained. The concentration value of methylene blue was then included in the percentage degradation formula (\% D).

\subsection{Determination of the optimum weight of Ceria, MS-Ce and MMS-Ce photocatalyst for photodegradation process of methylene blue}

Four $100 \mathrm{~mL}$ beker glasses which have been wrapped in black plastic each filled with $100 \mathrm{~mL}$ of $20 \mathrm{ppm}$ methylene blue solution. In each glass the beaker was added 0.10,20,30,40 and 50 mg Ceria, MS-Ce and MMS-Ce and one glass beaker without catalyst. The glass beaker was inserted into the radiation box and the black plastic wrap was released. Then the glass beaker was irradiated with Visibel lamp for optimum time, during the irradiation process with Visible light the solution is stirred with a magnetic stirrer. After the radiation process, the suspension of each beker glass was centrifuged at a speed of $4000 \mathrm{rpm}$ for 10 minutes. The solution was then decanted to separate the supernatant and sediment. The supernatant obtained from each glass beaker measured its absorbance by UV-Vis spectrophotometer at the maximum wavelength of methylene blue. The absorbance value obtained was then entered into the linear regression equation of the methylene blue solution, so that the methylene blue concentration was obtained. The concentration value of methylene blue was then included in the percentage degradation formula (\% D).

\subsection{Determination of the effectiveness of the methylene blue pho- todegradation process}

Three $100 \mathrm{~mL}$ beker glasses which have been wrapped in black plastic each filled with $50 \mathrm{~mL}$ of $20 \mathrm{ppm}$ methylene blue solution. Into each glass beaker included an optimum number of Ceria, MS-Ce and MMS-Ce. The glass was inserted into the radiation box and the black plastic wrap was released. Then the glass beaker was irradiated with UV light for optimum time, during the irradiation process with UV light the solution is stirred with a magnetic stirrer. After the radiation process, the suspension of each beker glass was centrifuged at a speed of $4000 \mathrm{rpm}$ for 10 minutes. The solution was then decanted to separate the supernatant and sediment. The supernatant obtained from each glass beaker measured its absorbance by UV-Vis spectrophotometer at the maximum wavelength of methylene blue. The absorbance value obtained was then 
entered into the linear regression equation of the methylene blue solution, so that the methylene blue concentration was obtained.

\section{Results and Discussion}

\subsection{Crystal structure analysis}

The results of crystal structure analysis of MS-Ce, MMS-Ce and Cerium oxide can be seen from Fig. 1 . The peak intensity of cerium oxide $(\mathrm{CeO} 2)$ was absorbed in $2 \theta$ angle $28,7^{\circ}, 33,2^{\circ}, 47,5^{\circ}, 56,7^{\circ}, 59.2^{\circ}, 69.5^{\circ}, 76.8^{\circ}, 79.1^{\circ}, 88.3^{\circ}$, and $95.5^{\circ}$. Its crystal lattices are 110, 200, 220, 311, 222, 400, 331, 420, 422 and 511 based on the JCPDS standard. 00-043-1002. The peak intensity of MS and MMS was absorbed in an angle of $2 \theta$ ie $23.5^{\circ}$ and $24.5^{\circ}$. The results of this study are along with the research conducted by Bing et al., 2011 [8] suggesting that mesoporous silica (MCM-41) obtained a specific peak at $2 \theta$ angle between $20-25^{\circ}$ when analyzed with Wide Angle XRD [8, 9]. The Ceria XRD pattern encapsulated in mesoporous silica (MS) and modified mesoporous silica (MMS) shown similar XRD pattern compared with the peak of nanocrystalline cerium oxide, only increases at peak shift and peak intensity. Based on the results of the study it can be assumed that Ceria has been homogeneously dispersed into the mesopores silica.

\subsection{Functional group analysis}

Fig. 2 illustrates the FTIR results of the resulting material. The success of the encapsulation process can be seen by comparing the FTIR spectrum of the material before and after the encapsulation process. Comparison of MS and MMS peaks can be seen in Table 1.

TABLE 1: The Assignments of the bands in the FTIR spectra of of MS and MMS materials.

$\begin{aligned} & \text { Wavenumber } \\ & \left(\mathbf{c m}^{-1}\right)\end{aligned}$
3414
1635
1060
805
471

\begin{tabular}{c} 
MS \\
\hline$v O H(\mathrm{Si}-\mathrm{OH})$ \\
\hline$\delta \mathrm{OH}(\mathrm{Si}-\mathrm{OH})$ \\
\hline$v a s(\mathrm{Si}-\mathrm{O}-\mathrm{Si})$ \\
\hline$v s(\mathrm{Si}-\mathrm{O}-\mathrm{Si})$ \\
\hline$\delta(\mathrm{Si}-\mathrm{O}-\mathrm{Si})$ \\
\hline
\end{tabular}

\begin{tabular}{|c|} 
Wavenumber $\left(\mathrm{cm}^{-1}\right)$ \\
\hline 3657 \\
1852 \\
1059 \\
801 \\
577
\end{tabular}

\section{MMS} $v \mathrm{OH}(\mathrm{Si}-\mathrm{OH})$ $\delta \mathrm{OH}(\mathrm{Si}-\mathrm{OH})$ $\operatorname{vas}(\mathrm{Si}-\mathrm{O}-\mathrm{Si})$ Vs (Si-O-Si) $\delta(\mathrm{Si}-\mathrm{O}-\mathrm{Si})$ 


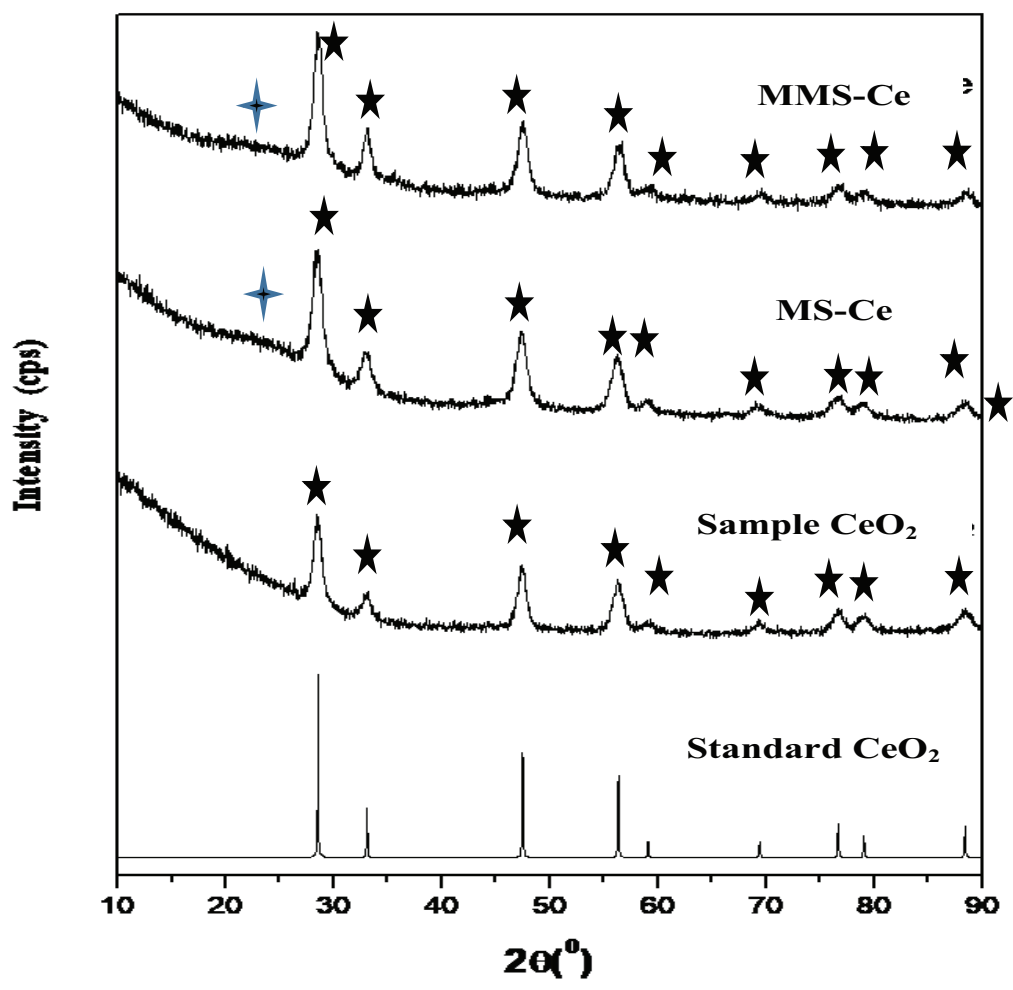

$\star \quad: \mathrm{CeO}_{2}$

+ : Silica amor

Figure 1: The Comparison Result of Wide Angle X-ray Diffraction of Materials.

The FTIR spectrum of MS-Ce and MMS-Ce almost the same as for the FTIR spectrum of MS and MMS but there is only a slight peak shift, decreasing peak intensity and some peak loss. The absorption of the Ce-O stretching bond also occurs at the wavelength $400-600 \mathrm{~cm}^{-1}$ and cannot be clearly distinguished by vibration bending (Si-O-Si). The Vibration $\delta(\mathrm{Si}-\mathrm{O}-\mathrm{Si}$ ), vs (Si-O-Si), vas(Si-O-Si), $\mathrm{VOH}(\mathrm{Si}-\mathrm{OH})$ dan $\delta \mathrm{OH}(\mathrm{Si}-\mathrm{OH})$ [10] in MS and MMS experience wavelength because of the electropositive cerium ion encapsulation of the electronegative oxygen atoms in the mesoporous silica nanoparticles shown in Fig. 2.

\subsection{DRS-UV VIS}

Determination of optical band gap energy is done by using the reflactant value from the DRS-UV Vis analysis. The\% refractant value (\% $\mathrm{R})$ is made into the $y$ axis by changing it to $R$. The value of the wavelength $(\lambda)$ from the results of the reflactant analysis with the DRS-UV Vis tool is included in the Kubelka Munk equation (Eq. 1), after which the value of $h v$ is searched with the equation (2) where $h$ is the plank constant $=6.626 \times 10-34$ $\mathrm{Js}$ and $C$ is the speed of light with a value of $3 \times 108 \mathrm{~m} / \mathrm{s}$. The value of alpha square $((1-R) 2 / 2 R \times h f) 2$ for each wavelength $(\lambda)$ was made into the $y$ axis and then plotted 


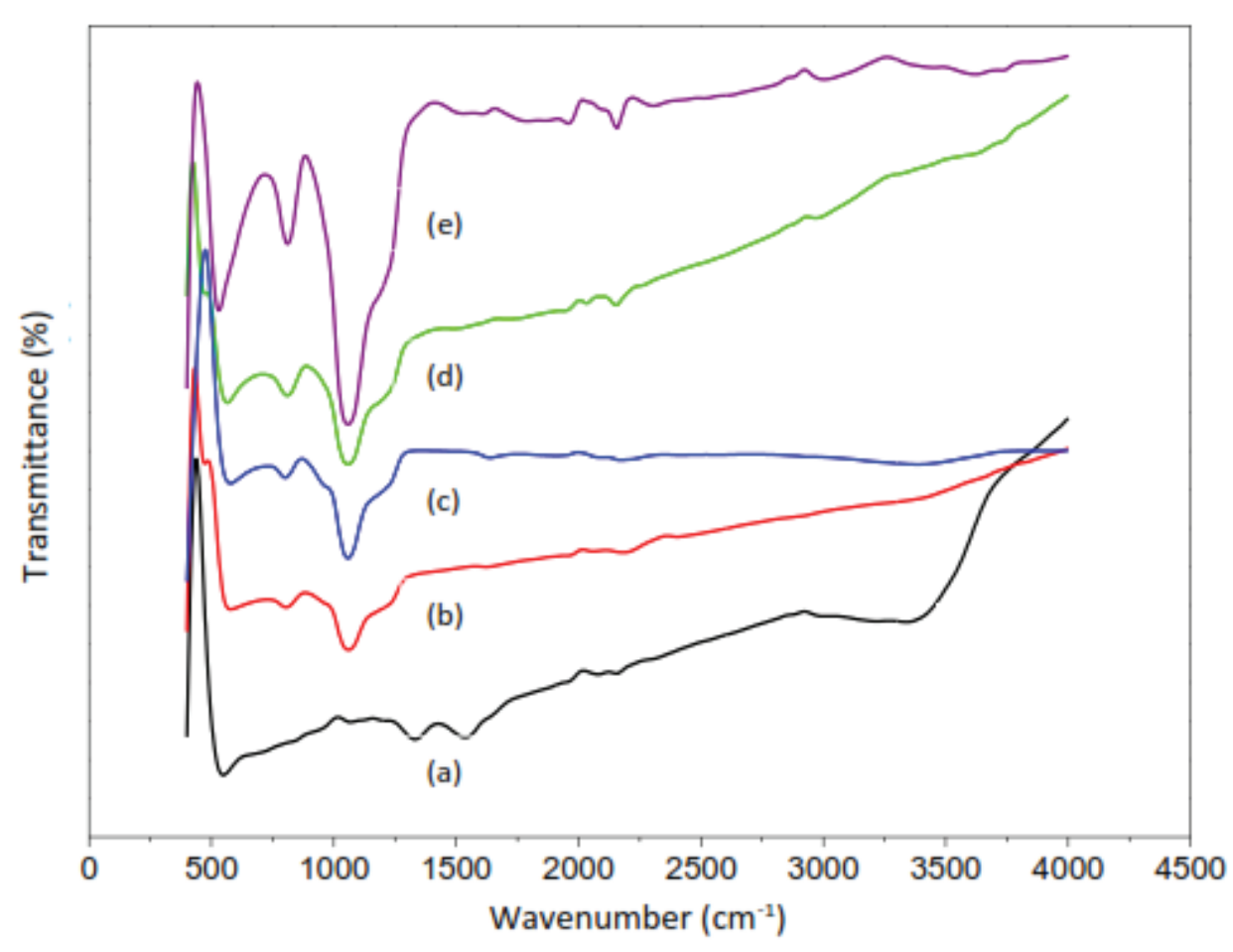

Figure 2: FTIR spectrum of (a) Cerium Oksida (Ceria) (b) Mesoporous Silica (MS) (c) Mesoporous SilicaCerium (MS-Ce) (d)Modified Mesoporous Silica (MMS) (e) Modified Mesoporous Silica - Cerium (MMS-Ce).

into the graph with the $\mathrm{x}$-axis Energy value in eV units [11]. After making a graph the relationship between alpha square ((1-R) $2 / 2 \mathrm{R} \times \mathrm{hf}) 2$ with the hv value drawn by a line that intersects with the turning point on the curve as shown in Fig. 3.

$$
\begin{gathered}
F(R)=\frac{(1-R)^{2}}{2 R} \\
E=\frac{h \cdot C}{\lambda}
\end{gathered}
$$

In nanomaterials the size of the material was very small so that the surface area becomes large. Energy band gap width is inversely proportional to particle size. The smaller the particle size, the greater the value of the energy band gap [12]. The greater the value of the energy band gap, the slower the recombination process will occur, so that the excitation process lasts longer than the recombination process, so that more organic compounds can be degraded [13]. The smaller the particle size, the more reactivity will increase because the smaller the particle size, the greater the surface area will cause more atomic fractions on the surface while a material reacts with other materials on the surface, so that the more atomic fractions on the surface, the reactivity of the material will increase $[12,14]$. The bulk band gap value of cerium oxide is ranging from 2.8 to $3.2 \mathrm{eV}$. 


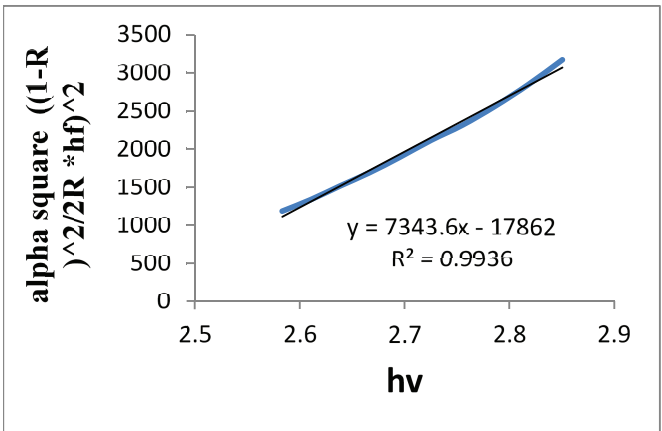

(a)

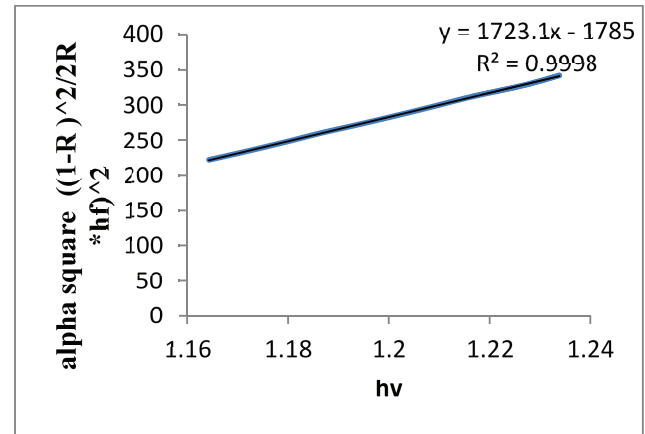

(b)

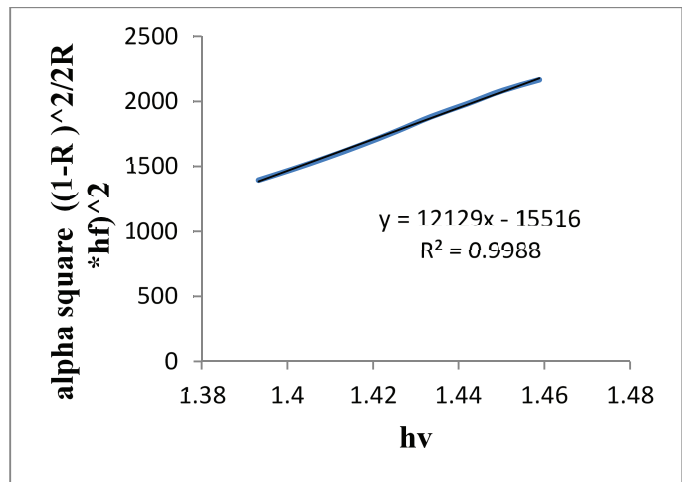

(c)

Figure 3: Curve Determination Energy Band Gap (a) cerium oxide (b) Mesoporous Silica-Cerium(SM-Ce) (c) Modified Mesoporous Silica-Cerium(MMS-Ce) with Kubelka-Munk theory.

Based on the results of the calculation of the energy band gap value in accordance with Fig. 3, the value of the energy band gap decreased to $2.43 \mathrm{eV}$. One way to improve the photocatalytic properties of semiconductors in the degradation process is done by modification to extend the excitation period and avoid recombination speed. Modification was done by doping semiconductor material. In this study cerium was doped with mesopori silica and modified mesoporous silica. The efficiency of semiconductors can be increased by doping. Through doping the value of energy band gap (band gap) can be reduced. Metal ions and doping compounds can act as electron trappers so that the excitation time becomes longer and recombination does not occur quickly. In the study the value of cerium energy band gap doped mesoporous silica fell to $1.03 \mathrm{eV}$. The value of cerium oxide energy band gap doped with mesoporous silica modification also decreased to $1.27 \mathrm{eV}$. With a smaller band gap value, effective photocatalysts are used in visible light because only $5 \%$ of UV light from the sun reaches the earth, while $45 \%$ of visible light from the sun reaches the earth [15]. 


\subsection{Catalytic activity}

The resulting photocatalyst is used to decompose the methylene blue dye with Visibel light. Visible beam sources use fluorescent lamps whose wavelengths are $351.4 \mathrm{~nm}$ $-698.2 \mathrm{~nm}$. The resulting photocatalyst was tested for the optimum conditions of the photocatalyst application to degrade the methylene blue solution. In this photocatalyst application determine the optimum weight, time and effectiveness of Ceria, MS-Ce and MMS-Ce photocatalyst for photodegradation of methylen blue.

\subsection{Determination of the optimum time of Ceria, MS-Ce and MMS-Ce photocatalyst for photodegradation process of methylene blue}

Cerium Oxide was used as a photocatalyst because of it was semiconductor properties. Photocatalyst was a catalyst process used visible or UV light. Before determining the percentage of dyestuff degradation, the maximum wavelength of the methylene blue solution was determined first. The maximum wavelength is determined by measuring the absorbance value of a $2 \mathrm{ppm}$ methylene blue solution at a wavelength of 550 $700 \mathrm{~nm}$. From the measurement results obtained the maximum wavelength of $2 \mathrm{ppm}$ blue methyl solution was $663 \mathrm{~nm}$ with an absorbance value of 0.41547 . The maximum wavelength of this blue methylene solution will be used to measure the absorbance of the blue methylene solution in future studies. After that, a calibration curve is made by measuring the absorbance values of several concentrations of standard methylene blue solutions 0, 1, 2, 3 and $4 \mathrm{ppm}$ at a maximum wavelength of $663 \mathrm{~nm}$. Based on the calibration curve obtained the correlation coefficient $(r)=0.996$. The $r$ value close to 1 shows the linear relationship between concentration and absorbance. The linear regression equation obtained was $y=0.1632 x-0.0065$. The equation will be used to calculate the concentration of methylene blue solution by entering its absorbance value.

Determine optimum time of Ceria, MS-Ce and MMS-Ce Photocatalyst used $50 \mathrm{mg}$ with photocatalysis processing time of $30,60,90,120,150,180,210,240,270$, and 300 minutes while being sterilized and exposed to visible light shown in Fig. 4. Photocatalyst process uses visible light from fluorescent lamps and photocatalyst boxes. The results of the optical condition test when it was found that the optimum time of degradation of methylene blue using ceria photocatalyst was150 minutes, MS-Ce 300 minutes and MMS-Ce 120 minutes. Base on this data showed that MMS-Ce give the shortets time to degradation methylene blue. 


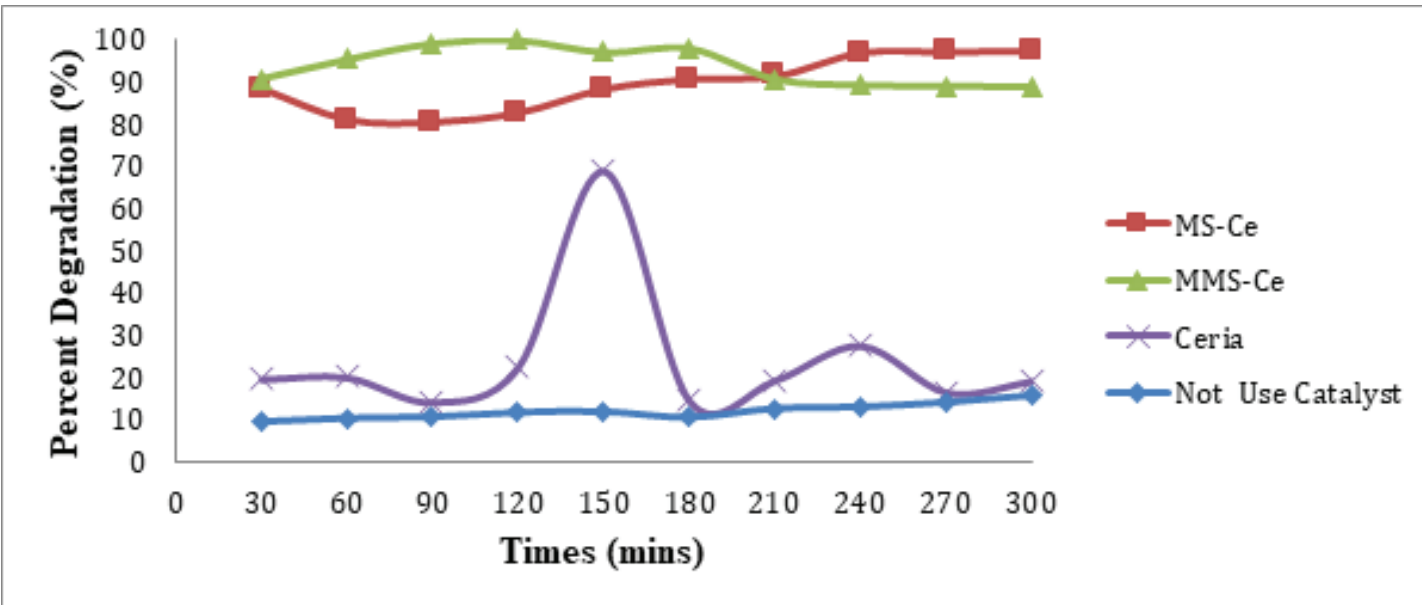

Figure 4: Curve of the optimum time of Ceria, MS-Ce and MMS-Ce photocatalyst for photodegradation process of methylene blue.

\subsection{Determination of the optimum weight of Ceria, MS-Ce and MMS-Ce photocatalyst for photodegradation process of methylene blue}

Based on the optimum time we determine the optimum weight of photocatalyst in degrading methylene blue. The weight of the photocatalyst that used were 10, 20.30, 40 and $50 \mathrm{mg}$. Ceria photocatalysts were tested for optimum weight in a radiation time of 150 minutes. MS-Ce photocatalyst was tested for optimum weight in 300 minutes of radiation time. Photocatalyst MMS-Ce was tested for optimum weight in a radiation time of 120 minutes. Fig. 5 showed that the optimum weight of Ceria, MS-Ce and MMS-Ce were $50 \mathrm{mg}, 50 \mathrm{mg}$ and $40 \mathrm{mg}$. Base on this data showed that weight of MMS-Ce give the littlest to degradation methylene blue.

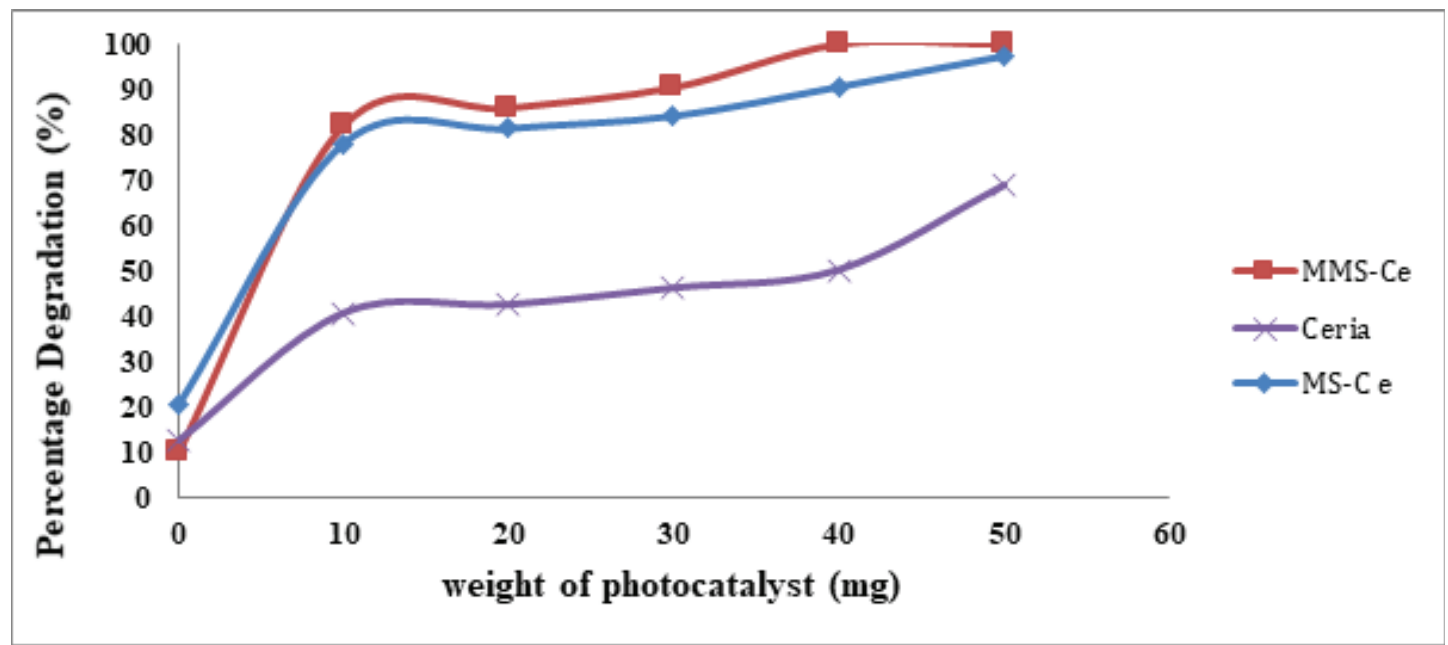

Figure 5: Curve of the optimum weight of Ceria, MS-Ce and MMS-Ce photocatalyst for photodegradation process of methylene blue. 


\subsection{Determination of the effectiveness of the methylene blue pho- todegradation process}

The effectiveness of Ceria photocatalyst in degrading methylene blue dye by using as much as $50 \mathrm{mg}$ of Ceria photocatalyst with a 150-minute irradiation time can degrade $68.85 \%$ of the dye. SM-Ce was able to degrade as much as $97.38 \%$ by using $50 \mathrm{mg}$ of photocatalyst SM-Ce with irradiation time of 300 minutes. The MMS-Ce photocatalyst was able to degrade as much as $99.98 \%$ with a long irradiation of 120 minutes shownin Fig. 6. The number of MMS-Ce photocatalysts used is $40 \mathrm{mg}$. Of the three photocatalysts, the MMS-Ce photocatalyst is best at degrading dyes with fewer photocatalysts and shorter radiation times and more degraded dyes.

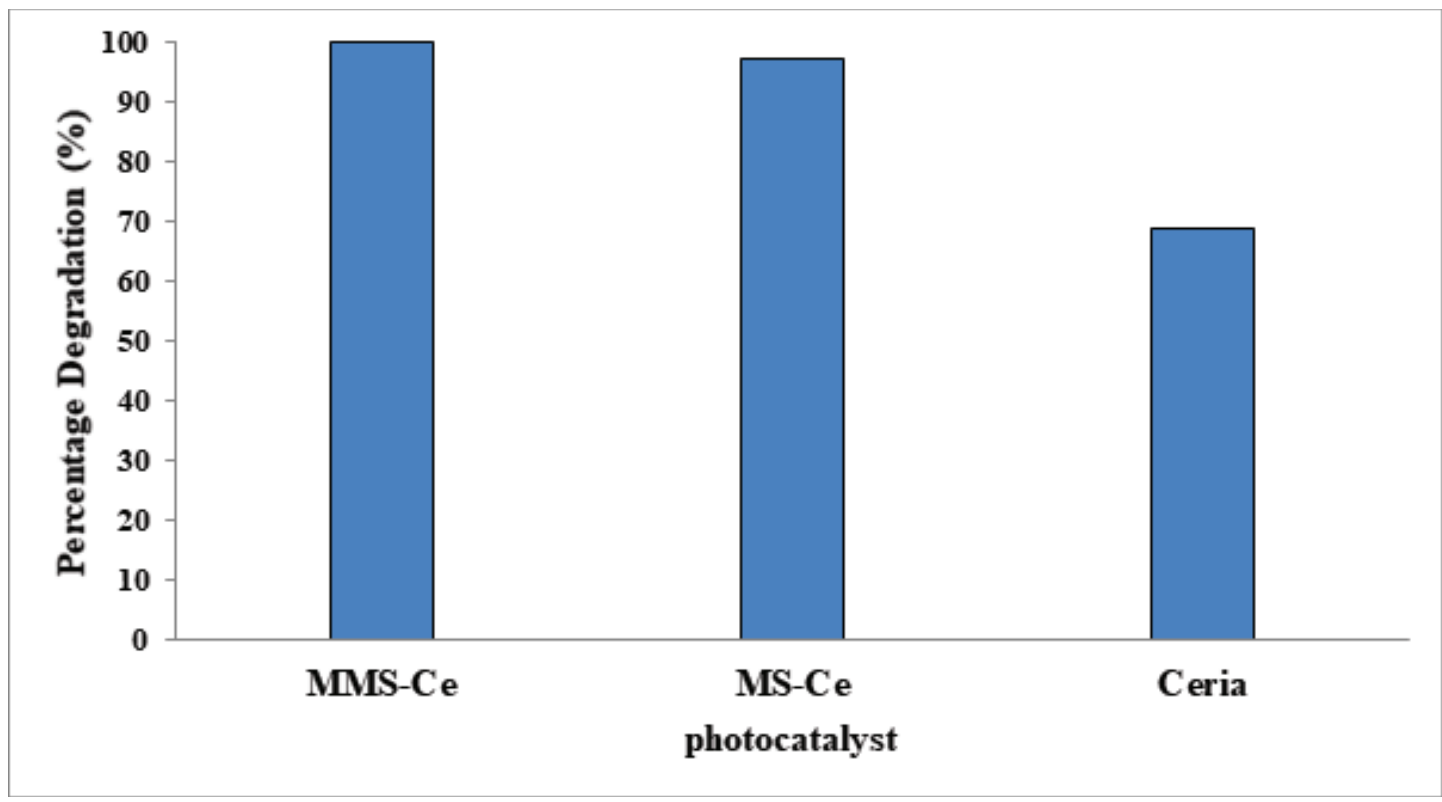

Figure 6: Histogram of the effectiveness of the methylene blue photodegradation process.

\section{Conclusions}

The photocatalytic activity of cerium oxide increases after being doped with mesoporous silica. DRS UV VIS Analysis showed that Cerium oxide nanoparticles band gap value of $2.43 \mathrm{eV}$ and mesoporous silica band gap value $1.27 \mathrm{eV}$. The smaller bandgap result in effective photocatalysts used in visible light. The results showed that the optimum conditions obtained were the optimum catalyst weight of Ceria, MS-Ce and MMS-Ce,were $50 \mathrm{mg}, 50 \mathrm{mg}$ and $40 \mathrm{mg}$. The optimum time for Ceria, MS-Ce and MMSCe photocatalyst degrades used visible light was 150 minutes, 300 minutes and 120 
minutes. Effectiveness of methylene blue degradation using Ceria, MS-Ce and MMS-Ce photocatalysts was $68.85 \%, 97.38 \%$ and $99.98 \%$.

\section{Acknowledgments}

The authors are thankful to Direktorat Riset Penelitian dan Pengabdian Kepada Masyarakat (DRPM) Direktorat Jenderal Pendidikan Tinggi (DIKTI) Indonesia that has funded this research, Koordinasi Perguruan Tinggi Wilayah $X$ (Kopertis $X$ ), Sekolah Tinggi IImu Kesehatan SYEDZA SAINTIKA and Chemistry Department of Universitas Andalas.

\section{References}

[1] S. Parsons. (2004). Advanced Oxidation Processes for Water and Waste Water, IWA Publishing.

[2] H.W., Choi, K.H., Lee, N.H., Hur, H.B., Lim. Cerium oxide-deposited mesoporous silica nanoparticles for the determination of carcinoembryonic antigen in serum using inductively coupled plasma-mass spectrometry (2014). Analytica Chimica Acta. 847.10-15.

[3] E.K., Goharshadi, S. Samiee, P. Nancarrow. Fabrication of cerium oxide nanoparticles: Characterization and optical properties (2011). Journal of Colloid and Interface Science.356. 473-480.

[4] Sen, Ranjan, Das, Sidartha, Das, Karabi. Microstuctural Characterization of Nanosized Ceria Powder by X-Ray diffraction Analysis (2010), Departemen of Metallurgical and Materials Engineering, Indian Institite Of Technology, Kharagpur, India.

[5] M. Muruganandham,M. Swaminathan, Photocatalytic decoloration and degradation of Reactive Orange 4 by TiO2-Vprocess (2006). Dyes Pigm. 68.133-142.

[6] A.F. Caliman, C. Cojocaru, A. Antoniadas, I. Poulios, (2007). Optimized photocatalytic degradation of Alcian Blue $8 \mathrm{GX}$ in the presence of $\mathrm{TiO} 2$ suspensions, J. Hazard.Mater. 144.265-273.

[7] X.R. Xu, H.B. Li, J.D. Gu. (2006). Simultaneous decontamination of hexavalent chromium and methyl tert-butyl ether by UV/TiO2 process, Chemosphere 63.254260. 
[8] D.H. Bremner, R. Molina, F. Martínez, J.A. Melero, Y. Segura,(2009) Degradation of phenolic aqueous solutions by high frequency sono-Fenton systems (USFe2O3/SBA-15-H2O2), Appl. Catal. B: Environ. 90.380-388.

[9] Carillo, A.I.; Serrano, E.; Serrano-Ruiz, J.C.; Luque, R.; Garcia-Martinez, J. Helical. (2012). Al- and Ce-MCM-41 materials as novel catalyst for acid and redox processes. Appl. Catal. A Gen.435-436, 1-9.

[10] Timofeeva, M.N.; Jhung, S.H.; Hwang, Y.K.; Kim, D.K.; Panchenko, V.N.; Melgunov, M.S.;Chesalov, Y.A.; Chang, J.-S.(2007). Ce-silica mesoporous SBA-15-type materials for oxidative catalysis:Synthesis, characterization, and catalytic application. Appl. Catal. A Gen. 317, 1-10.

[11] Bing, J.; Zeng, J.; Liao, G.; Li, X.; Lan, B.; Zhang, Q.; Li, L.(2012). Synthesis of ceriumdoped MCM-41for ozonation of p-chlorobenzoic acid. Environ. Chem. 31, 653-657.

[12] Akondi, A.M.; Trivedi, R.; Sreedhar, B.; Kantam, M.L.; Bhargava, S.(2012) Ceriumcontaining MCM-41 catalyst for selective oxidative arene cross-dehydrogenative coupling reactions. Catal.Today.198, 35-44.

[13] S.K. Muduli, S. Wang, N.G.Chen, C.F., Huan, C.H.A.H., Sum, T.C., H.S. Soo. Mesoporous cerium oxide nanospheres for the visible-light driven photocatalytic degradation of dyes (2014). Beilstein J. Nanotechnol. 5. 517-523.

[14] G.O.A.Vargas, J.A. De los Rayes Heredia, A.,Montesinos Castellanos, L.F. Chen, J.A. Wang. Cerium Incoperating Into MCM-41 Mesoporous Materials For CO Oxidation (2014). Materials Chemistry and Physics.139.125-133.

[15] P. Kalita, N.M. Gupta, R. Kumar, R. Solvent-free Mukaiyama-aldol condensation catalyzed by Ce-Al-MCM-41 mesoporous materials (2011). Microporous Mesoporous Mater.,144, 82-90. 